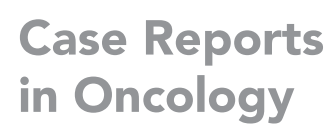

Case Reports

in Oncology

This article is licensed under the Creative Commons Attribution-NonCommercial 4.0 International License

\title{
Ileocecal Burkitt's Lymphoma Presenting as Acute Abdominal Pain
}

\author{
Mostafa Mosbeh Abdelmaksoud Maram Kheder Alshareef \\ Alaa Osama Jamjoom Mohamed Tarek Hafez \\ General Surgery Department, East Jeddah General Hospital, Jeddah, Saudi Arabia
}

\section{Keywords}

Non-Hodgkin's lymphoma · Gastrointestinal tract tumor · lleocecal lymphoma

\section{Abstract}

Primary gastrointestinal non-Hodgkin's lymphomas are rare tumors which account for about $0.9 \%$ of all gastrointestinal tract tumors. They are usually associated with inflammatory bowel disease, previous radiotherapy, and renal transplantation. We report a case of non-Hodgkin's lymphoma involving the ileocecal region in a 46-year-old gentleman who presented with acute abdominal pain that mandated emergency laparotomy.

\section{Background}

Among all non-Hodgkin's lymphomas, gastrointestinal lymphoma accounts for $5-10 \%$ of cases, intestinal lymphoma contributing 15-20\% [1]. The majority of these cases arise in the stomach (up to $65 \%$ of all gastrointestinal lymphomas), followed by the small bowel (20-30\%), with the rest arising in the colon and rectum [1-4]. B-cell lymphoma of the colon is one of the commonest malignancies of the colon, after carcinoma and carcinoid, though its incidence is rare at less than $0.5 \%$ [5]. Owing to its anatomical location, ileocecal lymphomas mostly present with complications, such as intestinal obstruction, which mandates surgical intervention on an emergency basis [6-8]. 
Fig. 1. CT scans of the abdomen and pelvis with double contrast.
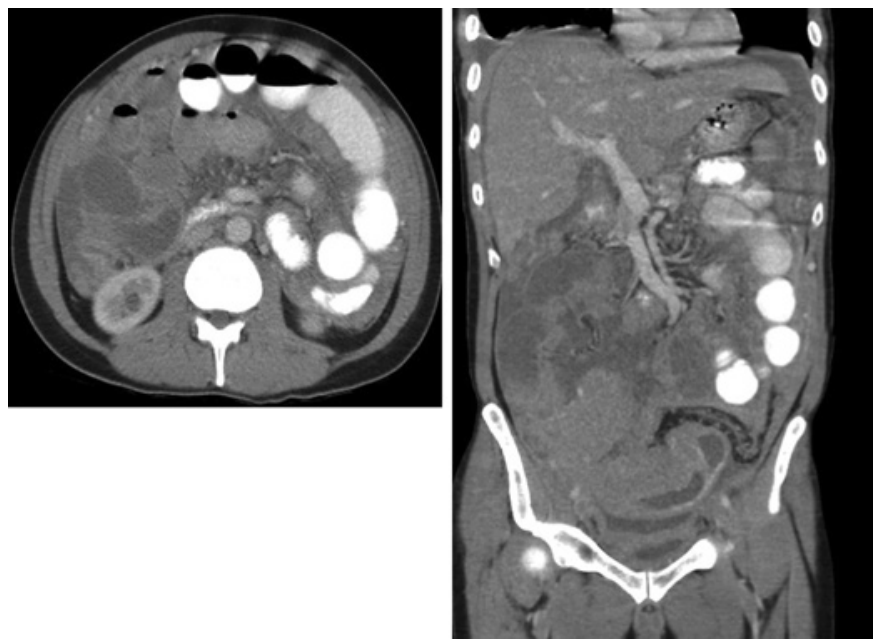

\section{Case Presentation}

A 46-year-old gentleman presented to our emergency department with a 7-day history of generalized abdominal pain associated with abdominal distension, in addition to multiple attacks of vomiting and loose bowel motion. He denied any history of weight loss, chronic diarrhea, night sweats, or any past medical illness.

Upon examination, generalized abdominal distension was noticed, associated with generalized guarding and tenderness all over his abdomen, without any detected impulse at the hernial orifices.

Computerized tomography (CT) scanning of the abdomen and pelvis with double oral and IV contrast revealed a segmental mural wall thickening with increased enhancement involving distal ileal loops with a suspected soft tissue mass (Fig. 1), resulting in back dilatation of the jejunal and ileal loops in addition to multiple air-fluid levels within it. Moreover, intraperitoneal fluid collection and multiple mesenteric lymphadenopathy were noticed.

On laboratory work-up, the results showed leukocytosis of $26 \times 10^{3}$ and high serum creatinine $(1.3 \mathrm{mg} / \mathrm{dL})$ and $\mathrm{LDH}(>1,995 \mathrm{U} / \mathrm{L})$ levels. As a result, the patient was prepared for an emergent abdominal exploration as a case of small bowel obstruction, after anesthesia assessment and the patient's consent for surgery. Exploratory laparotomy was conducted via mid-line incision with identification of $1.5 \mathrm{~L}$ of intraperitoneal pus collection and a mass $5 \times 5 \mathrm{~cm}$ in size at the terminal ileum with a dirty omentum and multiple hard mesenteric lymph nodes. As a consequence, ileocecal resection was done, followed by primary ileocolic anastomosis. In addition, omentectomy was performed with biopsy of the peritoneum (Fig. 2).

The surgery was finalized after appropriate hemostasis and insertion of two intraabdominal drains. Postoperatively, the patient was shifted to the intensive care unit for 4 days, and then shifted to a regular room in stable condition.

Histopathological assessment of the excised specimens revealed a $9 \times 3 \mathrm{~cm}$ high-grade B-cell lymphoma (Burkitt's lymphoma) in the ileocecal region with involvement of all mesenteric lymph nodes, the omentum, and the peritoneal biopsy.

During the postoperative follow-up, the patient developed right-sided pleural effusion, which was managed by US-guided drainage with the insertion of a pig-tail catheter. Cytological analysis of the drained fluid revealed malignant cells. The patient was transferred to a tertiary care center for further management by adjuvant therapy.

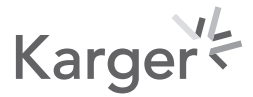


Fig. 2. Excised specimen involving the ileocecal region with its mesentery and part of the peritoneum.

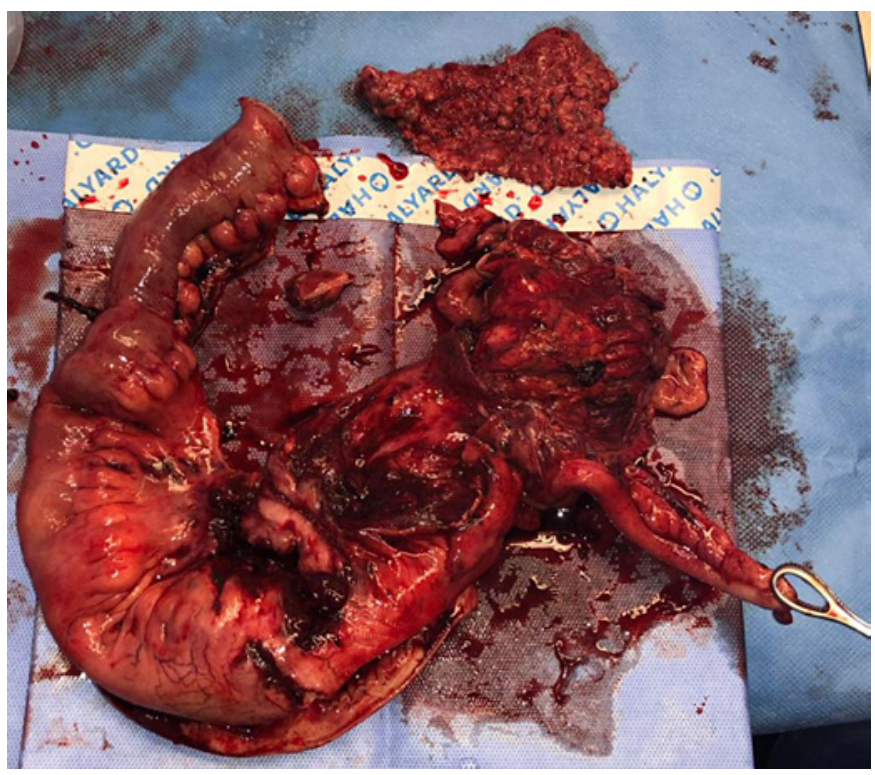

\section{Discussion}

According to the latest WHO classification, the B-cell lineage is categorized into five histological subtypes: extranodal marginal lymphoma, follicular lymphoma, mantle cell lymphoma, diffuse large B-cell lymphoma, and Burkitt's lymphoma [9].

Diffuse large B-cell lymphoma is the most frequent histological subtype, which affects the gastrointestinal tract and colon [10]. It consists of rapidly proliferating cells that are more aggressive than those of other B-cell lymphomas. Primary colorectal lymphoma occurs mainly in the older age groups in the 5th to 7th decades of life, with a male:female ratio of 1.5:1 [11].

The manifestation of B-cell lymphoma is varied and depends on the site of the lesion. Most commonly, there are abdominal pain, weight loss, an abdominal mass, and hematochezia, in addition to symptoms of obstruction, such as nausea, vomiting, change in bowel habits $[1,3]$, obstruction $[1,4]$, intussusceptions $[12,13]$, and acute peritonitis due to intestinal perforation $[1,3]$.

The Lugano classification is the most widely used staging system in clinical practice and is based on the Ann Arbor system modified by Carbone et al. [14]. Stage I describes involvement of only a single nodal group or single extranodal site (IE). Stage II entails involvement of more than one nodal group on the same side of the diaphragm or single extranodal site and adjacent lymph nodes (IIE). At stage III, there is involvement of multiple nodal sites on both sides of the diaphragm, including extranodal sites (IIIE) or the spleen (IIIS). Finally, stage IV includes involvement of the bone marrow or central nervous system, or diffuse visceral involvement [14].

The principal mode of treatment is the combined modality that consists of surgery and chemotherapy [15]. Early-stage tumors should be treated with surgery followed by polychemotherapy, while advanced-stage tumors are treated with multidrug chemotherapy $[1,3]$. Surgery is the primary modality for palliation of pain and emergent conditions like obstruction, perforation, and bleeding [16].

In our case, the patient presented with acute abdominal pain, for which an examination was performed, as well as ileocecal resection. Postoperative histopathological assessment of the excised specimens revealed non-Hodgkin's lymphoma in the ileocecal region with

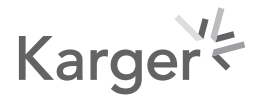


metastases to the omentum, peritoneum, and mesenteric lymph nodes, in addition to positive malignant cells in the US-guided aspirated fluid from the right-sided pleural effusion.

\section{Conclusions}

Primary ileocecal lymphoma is a rare clinical entity presenting most commonly in older age groups. Its presentation is often nonspecific, which leads to delayed diagnosis, and it may present as acute abdominal pain. The primary treatment modality is surgery followed by chemotherapy. The reported prognosis of colonic lymphoma is poor and recurrences are common; however, with use of R-CHOP, improved survival has been reported.

\section{Statement of Ethics}

This article was approved by the Research Committee of the Surgery Department at East Jeddah Hospital, and permission was obtained from the patient to publish all materials related to the case.

\section{Conflict of Interest Statement}

The authors declare no conflict of interest.

\section{Funding Sources}

This article is self-funded by the authors.

\section{Author Contributions}

M.T. Hafez: decision regarding clinical management, idea for the manuscript, and final revision. M.M. Abdelmaksoud: clinical management and writing of the manuscript. M.K. Alshareef: clinical management and data collection. A.O. Jamjoom: clinical management and revision of the manuscript.

\section{References}

1 Zinzani PL, Magagnoli M, Pagliani G, Bendandi M, Gherlinzoni F, Merla E, et al. Primary intestinal lymphoma: clinical and therapeutic features of 32 patients. Haematologica. 1997;82(3):305-8.

2 Doolabh N, Anthony T, Simmang C, Bieligk S, Lee E, Huber P, et al. Primary colonic lymphoma. J Surg Oncol. 2000;74(4):257-62.

3 Bairey 0, Ruchlemer R, Shpilberg O. Non-Hodgkin's lymphomas of the colon. Isr Med Assoc J. 2006;8(12): 832-5.

4 Gonzalez QH, Heslin MJ, Dávila-Cervantes A, Alvarez-Tostado J, de los Monteros AE, Shore G, et al. Primary colonic lymphoma. Am Surg. 2008;74(3):214-6.

5 Ladd AP, Grosfeld JL. Gastrointestinal tumors in children and adolescents. Semin Pediatr Surg. 2006;15(1): 37-47.

6 Kim YH, Lee JH, Yang SK, Kim TI, Kim JS, Kim HJ, et al. Primary colon lymphoma in Korea: a KASID (Korean Association for the Study of Intestinal Diseases) Study. Dig Dis Sci. 2005;50(12):2243-7.

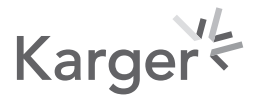


7 Auger MJ, Allan NC. Primary ileocecal lymphoma. A study of 22 patients. Cancer. 1990;65(2):358-61.

8 Sweetenham JW, Mead GM, Wright DH, McKendrick JJ, Jones DH, Williams CJ, et al. Involvement of the ileocaecal region by non-Hodgkin's lymphoma in adults: clinical features and results of treatment. Br J Cancer. 1989;60(3):366-9.

9 Harris NL, Jaffe ES, Diebold J, Flandrin G, Muller-Hermelink HK, Vardiman J. Lymphoma classification--from controversy to consensus: the R.E.A.L. and WHO Classification of lymphoid neoplasms. Ann Oncol. 2000;11 Suppl 1:3-10.

10 Koch P, del Valle F, Berdel WE, Willich NA, Reers B, Hiddemann W, et al. Primary gastrointestinal non-Hodgkin's lymphoma: I. Anatomic and histologic distribution, clinical features, and survival data of 371 patients registered in the German Multicenter Study GIT NHL 01/92. J Clin Oncol. 2001;19(18):3861-73.

11 Fan CW, Changchien CR, Wang JY, Chen JS, Hsu KC, Tang R, et al. Primary colorectal lymphoma. Dis Colon Rectum. 2000;43(9):1277-82.

12 Chiang JM, Lin YS. Tumor spectrum of adult intussusception. J Surg Oncol. 2008;98(6):444-7.

13 Zubaidi A, Al-Saif F, Silverman R. Adult intussusception: a retrospective review. Dis Colon Rectum. 2006; 49(10):1546-51.

14 Carbone PP, Kaplan HS, Musshoff K, Smithers DW, Tubiana M. Report of the Committee on Hodgkin's Disease Staging Classification. Cancer Res. 1971;31(11):1860-1.

15 Tondini C, Giardini R, Bozzetti F, Valagussa P, Santoro A, Bertulli R, et al. Combined modality treatment for primary gastrointestinal non-Hodgkin's lymphoma: the Milan Cancer Institute experience. Ann Oncol. 1993; 4(10):831-7.

16 Cai S, Cannizzo F Jr, Bullard Dunn KM, Gibbs JF, Czuczman M, Rajput A. The role of surgical intervention in non-Hodgkin's lymphoma of the colon and rectum. Am J Surg. 2007;193(3):409-12; discussion 412. 